\title{
斜学通极
}

\section{转人生长激素基因红鲤 $\mathbf{F}_{2}$ 代阳性鱼 的摄食及代谢研究 ${ }^{*}$}

\author{
崔宗斌 朱作言 $* *$ 崔奕波 李国华 许克圣
}

(中国科学院水生生物研究所, 武汉 430072)

\section{关键词转基因鱼 摄食 代谢}

生长激素 $(\mathrm{GH})$ 是由中腺垂体分泌的多功能激素, 对动物生长的促进效应已无可置疑. 将冠以小鼠重金属螯合蛋白 (MT-1) 基因启动顺序的人生长激素(hGH) 基因重组质粒 pMThGH 显微注射到红鲫 (Carassius auratus auratus) ${ }^{[1]}$ 和泥䲝 (Misgurnus anguillicaudatus) ${ }^{[2]}$ 的受精卵 内, 获得了第一批转基因鱼, 并进一步证实了转移基因的整合、表达、传代及转 GH 基因鱼的 快速生长效应 ${ }^{[3]}$. 由于鱼类自然群体中也存在个别的快速生长个体, 对转 $\mathrm{GH}$ 基因鱼快速生 长的生理学背景一直为国内外研究者们所关注. 本文对转 MThGH 基因红鲤 $F_{2}$ 代阳性鱼 的摄食和代谢进行了分析, 首次从生物能量学角度探讨了转 $\mathrm{GH}$ 基因鱼 “少食快长” 的生理 机制, 为转 $\mathrm{GH}$ 基因育种提供了理论依据.

\section{1 材料和方法}

\section{1 材料}

实验鱼为本实验室研制的转 $\mathrm{MThGH}$ 基因红鲤 (Cyprinus carpio L.) 的 $\mathrm{F}_{2}$ 代, 对照鱼为本 所实验场养殖的同种普通红鲤. 所用化学试剂购自 Sigma 公司.

\section{2 生长对比实验}

实验开始前, 将 2 月龄的实验鱼和对照鱼各 30 尾, 分别饲养在恒温 $(27 \pm 0.15)^{\circ} \mathrm{C}$ 的房间 $7 \mathrm{~d}$, 光照控制为 $12 \mathrm{~h} / \mathrm{d}$, 使它们适应这种实验条件. 铒料是活的水蚯蚓 (主要为 Limnodrilus hoffmeisteri), 实验开始前停饵 $2 \mathrm{~d}$. 实验开始之初, 用滤纸吸除鱼体表面多余的水分, 将 15 尾实 验鱼和 15 尾对照鱼称重后, 单个地饲养在盛 $12 \mathrm{~L}$ 曝气自来水的玻璃缸中, 进行生长对比实 验. 另外 15 尾实验鱼和 15 尾对照鱼在称重后被处死, 置 $70^{\circ} \mathrm{C}$ 干燥至恒重, 作为测定实验开 始时 2 组鱼的生化成分和能量含量之用. 经尾鯺 DNA 的聚合酶链反应 (PCR) 证实, 实验前 处死的 15 尾实验鱼中有 14 尾携带人 GH 基因, 用于生长对比实验的 15 尾实验鱼中有 12 尾 携带人 $\mathrm{GH}$ 基因, 即这批转基因红鲤 $\mathrm{F}_{2}$ 代携带外源基因的阳性率为 $86.7 \%$ (结果另文报道). 实验组中, 只有 PCR 阳性鱼 (即转 MThGH 基因红鲤 $\mathrm{F}_{2}$ 代阳性鱼, 简称 $\mathrm{F}_{2}$ 代阳性鱼) 个体才 用于统计分析. 实验持续 $21 \mathrm{~d}$. 每天上午投喂水蚯蚓, 投饵量以每尾鱼吃够并稍有余为度.

1994-12-12 收稿, 1995-04-10 收修改稿

“国家“八六三”高技术计划基金资助项目. 本文在淡水生态与生物技术国家重点实验室完成

**联系人 
同时, 称取一份水蚯蚓并置 $70^{\circ} \mathrm{C}$ 干燥, 用来测定其干物质和相应的能量含量. 第二天投饵前 清除余饵. 投饵和余饵均用滤纸吸除体表水分, 然后称重. 利用无鱼对照缸校正水蚯蚓在 $24 \mathrm{~h}$ 中的重量损失. 每天用吸管收集粪便 2 次, 收集的粪便置 $70^{\circ} \mathrm{C}$ 干燥备测定用.

\section{3 生化成分和能量分析}

每周更换一次鱼缸中的水, 在水质更新前后分别取样, 并采用 Chaney 和 Marbach 的方法 ${ }^{[4]}$ 测定水样中氨氮和尿氮的含量, 以此确定每尾鲁的氨氮和尿氮排泄量. 由无鱼对照缸测定水 蚯蚓的氨氮和尿氮排泄量, 以校正投饵对鱼的氨氮和尿氮排泄量值的影响. 鱼的排泄能量由 其排泄的氨氮和尿氮含量计算,氨氮和尿氮的热值采用 24.83 和 $23.03 \mathrm{~J} / \mathrm{mg}^{[S]} . \mathrm{F}_{2}$ 代阳性鱼和 对照鱼、水蚯蚓以及粪便等的干物质能量含量用氧弹热量计测定, 蛋白含量用弗林 - 酚法测 定, 脂肪含量用氯仿抽提法测定.

\section{4 统计分析}

采用 Kruskal-Wallis 检验分析 $\mathrm{F}_{2}$ 代阳性鱼与对照鱼在摄食、生长、生化组成和能量收支 方面的差异. 以湿重为例, 其特定生长率计算公式为 $\mathrm{SGR}_{\mathrm{w}}=100 \times\left[\left(\ln W_{\mathrm{t}}-\ln W_{0}\right) / t\right]$, 能 量、干 物质和蛋白质的特定生长率按同样公式计算. 摄食率的计算公式为 $C /\left[\left(W_{\mathrm{t}}-W_{0}\right) \times t\right]$, 其中 $W_{\mathrm{t}}$ 和 $W_{0}$ 分别为实验结束时和实验开始时鱼的湿重, $t$ 为实验持续的天数, $C$ 为鱼自食物中获得 的总能量. 干物质含量用占鱼体湿重的百分数表示. 转换效率表示生长量占摄食量的百分 比, 生长量及摄食量可以用湿重、干重、能量或蛋白质的量. 各生化成分的含量用占鱼体干重 的百分数表示．能量含量用每克干物质充分燃烧产生的热量值表示．

\section{2 结果和讨论}

\section{$2.1 \quad F_{2}$ 代阳性鱼和对照鱼的摄食及生长比较}

$F_{2}$ 代阳性鱼与对照鱼在摄食和生长方面的差异见表 1 . 与对照鱼比较, $F_{2}$ 代阳性鱼的摄 食率降低, 而其湿重、干重、能量和蛋白质等的特定生长率和转换效率均显著增高, 即转 MThGH 基因鱼有 “少食快长”的生理特性. 有研究发现, 注射动物 GH 不仅刺激银大麻哈鱼 (Oncorhynchus kisutch) 的生长而且提高其食物的转换效率. 我们用放射免疫法检测到人 $\mathrm{GH}$ 在 $\mathrm{F}_{2}$ 代阳性鱼中的存在 (结果另文发表), $F_{2}$ 代阳性鱼的这种少食快长特性, 应归因于 MThGH 基因的表达.

表 $1 \quad F_{2}$ 代阳性鱼和对照红鲤的摄食率、特定生长率及转换效率 ${ }^{a)}$

\begin{tabular}{lccc}
\hline & $\mathrm{F}_{2}$ 代阳性鱼 & 对照红鲤 & Kruskal-Wallis 分析 \\
\hline 测定鱼数 & $n=12$ & $n=15$ & \\
摄食率 $/ \mathrm{kJ} \cdot \mathrm{g}^{-1} \cdot \mathrm{d}^{-1}$ & $0.603 \pm 0.014$ & $0.649 \pm 0.012$ & $p<0.05$ \\
湿重特定生长率 $/ \% \cdot \mathrm{d}^{-1}$ & $6.82 \pm 0.16$ & $6.04 \pm 0.14$ & $p<0.01$ \\
干重特定生长率 $/ \% \cdot \mathrm{d}^{-1}$ & $7.34 \pm 0.18$ & $6.63 \pm 0.13$ & $p<0.01$ \\
能量特定生长率 $/ \% \cdot \mathrm{d}^{-1}$ & $8.14 \pm 0.20$ & $7.17 \pm 0.15$ & $p<0.01$ \\
蛋白质特定生长率 $/ \% \cdot \mathrm{d}^{-1}$ & $7.59 \pm 0.16$ & $6.48 \pm 0.16$ & $p<0.001$ \\
湿重转换效率 $/ \%$ & $30.96 \pm 0.70$ & $28.75 \pm 0.54$ & $p<0.05$ \\
干重转换效率 $/ \%$ & $43.83 \pm 1.24$ & $40.43 \pm 0.65$ & $p<0.05$ \\
能量转换效率 $/ \%$ & $41.44 \pm 0.89$ & $38.13 \pm 0.85$ & $p<0.05$ \\
蛋白质转换效率 $/ \%$ & $57.38 \pm 0.96$ & $47.41 \pm 1.08$ & $p<0.001$ \\
\hline
\end{tabular}

a) 数值以平均值 \pm 平均标准误表示 


\section{$2.2 F_{2}$ 代阳性鱼和对照鱼的能量收支比较}

鱼的能量收支式表示为 $G=C-F-U-R$, 其中 $G, C, F, U$ 和 $R$ 分别代表生长能量、摄 食能量、排粪能量、排泄能量和代谢能量 ${ }^{[6]}$. 依据此式, 下述原因有助于加快鱼的生长: (1) 摄 食能量增加；(2) 排粪能量占摄食能量的比例减小; (3) 排泄能量占摄食能量的比例减小; (4) 代谢能量占摄食能量的比例降低; (5) 上述因素综合的结果.

本实验测定了鱼的 $C, F, U$ 和 $G . R$ 为 $C$ 减去 $G, F$ 和 $U$ 的差值. $\mathrm{F}_{2}$ 代阳性鱼的能量收 支式为 $100 C=8.90 F+0.63 U+49.03 R+41.44 G$, 对照鱼的能量收支式为 $100 C=7.37 F+1.14 U+$ $53.36 R+38.13$ G. Kruskal-Wallis 分析发现, $\mathrm{F}_{2}$ 代阳性鱼生长能的利用和排粪能的损失显著 大于对照鱼,而其代谢能的消耗和排泄能的损失显著小于对照鱼 (表 2). 由于鱼的排粪能只 占总能量支出的很小一部分, 而代谢能消耗(约占摄食能的 $50 \%$ ) 的差异是影响鱼生长的主要 因素. 因此, 总的能量收支结果显示, 与对照鱼相比, $F_{2}$ 代阳性鱼多 $6.62 \%$ 的摄人能量用于积 累 (其中包括加速生长). 摄食能在生长能方面分配的增加, 即是食物转换效率的提高和饵料 系数的降低, $\mathrm{F}_{2}$ 代阳性鱼的这一少食快长的特点意味着转 $\mathrm{GH}$ 基因鱼在渔业生产上有应用前景.

表 $2 \mathrm{~F}_{2}$ 代阳性鱼和对照红鲤的能量收支 ${ }^{a)}$

\begin{tabular}{lccc}
\hline & $\mathrm{F}_{2}$ 代阳性鱼 & 对照红鲤 & Kruskal-Wallis 分析 \\
\hline 测定鱼数 & $n=12$ & $n=15$ & \\
$G \cdot C^{-1 / \%}$ & $41.44 \pm 0.89$ & $38.13 \pm 0.85$ & $p<0.05$ \\
$R \cdot C^{-1} / \%$ & $49.03 \pm 0.91$ & $53.36 \pm 0.98$ & $p<0.01$ \\
$F \cdot C^{-1} / \%$ & $8.90 \pm 0.53$ & $7.37 \pm 0.30$ & $p<0.05$ \\
$U \cdot C^{-1} / \%$ & $0.63 \pm 0.04$ & $1.14 \pm 0.08$ & $p<0.001$ \\
\hline
\end{tabular}

a) 数值以平均值 \pm 平均标准误表示. $G$ 为生长能量, $R$ 为代谢能量, $F$ 为排貲能量, $U$ 为排泄能量, $C$ 为摄食能量

\section{$2.3 \mathrm{~F}_{2}$ 代阳性鱼和对照鱼的生化成分及能量含皇比较}

实验开始时, $\mathrm{F}_{2}$ 代阳性鱼与对照鱼在干物质、蛋白质、脂肪和能量等的含量方面无显著差 异. 这可能与实验前材料鱼高密度饲养、缺氧和投饵受到限制有关. 在实验结束时, $\mathrm{F}_{2}$ 代阳 性鱼的蛋白质含量显著高于对照鱼, 而其干物质、脂肪和能量含量与对照鱼无显著差异 (表3).

表 $3 \mathrm{~F}_{2}$ 代阳性鱼和对照红鲤的生化成分及能量含量 ${ }^{\text {a) }}$

\begin{tabular}{lccc}
\hline & $\mathrm{F}_{2}$ 代阳性鱼 & 对照红鲤 & Kruskal-Wallis 分析 \\
\hline 实验开始时 & & & \\
测定鱼数 & $n=14$ & $n=15$ & \\
干物质 $/ \%$ & $19.65 \pm 0.26$ & $19.53 \pm 0.24$ & $p>0.05$ \\
蛋白质 $/ \%$ & $59.93 \pm 0.57$ & $58.40 \pm 0.51$ & $p>0.05$ \\
脂肪 $/ \%$ & $12.05 \pm 0.55$ & $11.90 \pm 0.29$ & $p>0.05$ \\
能量 $/ \mathrm{kJ} \cdot \mathrm{g}^{-1}$ & $18.71 \pm 0.25$ & $19.27 \pm 0.13$ & $p>0.05$ \\
\hline 实验结束时 & & & \\
测定鱼数 & $n=12$ & $n=15$ & \\
干物质 $/ \%$ & $21.95 \pm 0.36$ & $22.11 \pm 0.23$ & $p>0.05$ \\
蛋白质 $/ \%$ & $63.19 \pm 1.24$ & $56.61 \pm 0.53$ & $p<0.001$ \\
脂肪 $/ \%$ & $23.32 \pm 0.51$ & $23.97 \pm 0.57$ & $p>0.05$ \\
能量 $/ \mathrm{kJ} \cdot \mathrm{g}^{-1}$ & $22.16 \pm 0.29$ & $21.60 \pm 0.22$ & $p>0.05$ \\
\hline
\end{tabular}

a) 数值以平均值 \pm 平均标准误表示 
动物 $\mathrm{GH}$ 具有促进鱼蛋白质合成的功能. 例如, 牛 $\mathrm{GH}$ 能提高银大麻哈鱼肌肉的蛋白质 含量. 在本实验中, $F_{2}$ 代阳性鱼的蛋白质转换效率 (表 1)、排泄能占摄食能比例的显著降低 (表 2) 和干物质蛋白质含量 (表 3) 的提高, 都说明其蛋白质利用效率高, 即 MThGH 基因表达 的人 GH 有提高红鲤蛋白质合成的功能. 此外, 我们发现 $\mathrm{F}_{2}$ 代阳性鱼与对照鱼在干物质脂肪 含量方面无显著差异. $\mathrm{GH}$ 对鱼类脂代谢影响的研究结果不尽一致. 有报道指出, 注射 $\mathrm{GH}$ 导致金鱼 (Carassius auratus) 血浆中游离脂肪酸水平升高; 注射牛 $\mathrm{GH}$ 显著降低银大麻哈鱼 肌肉的脂肪含量, 说明 $\mathrm{GH}$ 具有促进脂解的活性. 然而, 莫桑比克罗非鱼 (Oreochromis mossambicus) 在注射牛 GH 后的血脂、胆固醇和肝脂等的含量无显著变化. 也有人发现, 注射 牛 $\mathrm{GH}$ 显著提高虹䲡 (Salmo gairdneri) 血游离脂肪酸水平, 但对肌肉脂肪含量没影响. 因 此, $\mathrm{GH}$ 对鱼类脂代谢影响的这些差别可能与 $\mathrm{GH}$ 来源、受体鱼种类及实验持续时间不同有 关.

\section{参考文献}

1 Zhu Z, Li G, He L et al. Novel gene transfer into the fertilized eggs of gold fish (Carassius auratus L. 1758). Z Angew Ichthyol, 1985, 1:31 34

2 朱作言, 许克圣, 李国华等. 人生长激素基因在泥受精卵显微注射转移后的生物学效应. 科学通报, 1986, 31(5): $387 \sim 389$

3 朱作言, 许克圣,谢岳峰等. 转基因鱼模型的建立. 中国科学, B 辑, 1989, (2): 147 155

4 Chaney A L, Marbach E P. Modified reagents for determination of urea and ammonia. Clin Chem, 1962, 8:130 132

5 Elliott J M. Energy losses in the waste products of brown trout (Salmo trutta L.) in relation to temperature and ration size. J Anim Ecol, 1976, 45: 561 580

6 Brett J R, Groves T D D. Physiological energetics. In: Hoar W S ed. Fish Physiology. London: Academic Press, 1979. VIII: $279 \sim 352$ 